\section{Birlesik Dünya Arastırma New Trends and Issues BD-CENTER Proceedings on Humanities and Innovasyon ve Yayıneilık Merkezi \\ Social Sciences}

Volume 7, Issue 3, (2020) 130-141

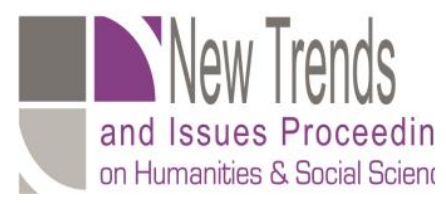

Selected Paper of 9th Cyprus International Conference on Educational Research (CYICER-2020) 18-20 June 2020, Bahçeşehir Cyprus University Nicosia / TRNC (ONLINE CONFERENCE)

\title{
Implementation of dance therapy in 13-14 year old students in order to reduce stress and anxiety
}

Florina Emilia Grosu*, Individual Sports - Faculty of Physical Education and Sport, Physical Education and Sport Faculty Romania, Babes - Bolyai University, Strada Mihail Kogalniceanu 1, 400000 Cluj-Napoca, Romania https://orcid.org/0000-0002-2846-9586

Vari Hanna Imola, Individual Sports - Faculty of Physical Education and Sport, Physical Education and Sport Faculty Romania, Babes - Bolyai University, Strada Mihail Kogalniceanu 1, 400000 Cluj-Napoca, Romania

Mihaiu Costinel, Individual Sports - Faculty of Physical Education and Sport, Physical Education and Sport Faculty Romania, Babes - Bolyai University, Strada Mihail Kogalniceanu 1, 400000 Cluj-Napoca, Romania

Grosu Vlad Teodor, Technical University \& Cluj - Napoca, Babes - Bolyai University, Strada Mihail Kogalniceanu 1, 400000 Cluj-Napoca, Romania

Moisa Turcu Antonel Adrian, Individual Sports - Faculty of Physical Education and Sport, Physical Education and Sport Faculty Romania, Babes - Bolyai University, Strada Mihail Kogalniceanu 1, 400000 Cluj-Napoca, Romania

\section{Suggested Citation:}

Grosu, F. E., Imola, V. H., Costinel, M., Teodor G. V. \& Adrian, M. T. A. (2020). Implementation of dance therapy in 13-14 year old students in order to reduce stress and anxiety. New Trends and Issues Proceedings on Humanities and Social Sciences. 7(3), pp 130-141. Available from: www.prosoc.eu

Received from June 28, 2020; revised from August 15, 2020; accepted from November 23, 2020.

Selection and peer review under responsibility of Prof. Dr. Huseyin Uzunboylu, Higher Education Planning, Supervision, Accreditation and Coordination Board, Cyprus.

${ }^{\circledR} 2020$ Birlesik Dunya Yenilik Arastirma ve Yayincilik Merkezi. All rights reserved.

\begin{abstract}
Problem statement: Investigating numerous articles and studies on the effects of dance on the body, we can say that this type of movement brings many benefits to our health both physically and mentally regardless of the age. Purpose of study: This paper aims to analyse the level of stress in students aged 13-14 years, as well as reducing the level of stress felt by them by applying dance therapy. Study hypothesis: Indicators of stress (such as anxiety, emotional distress, etc.) can be improved with a focused dance-intervention therapy program, created specifically for this purpose. Objectives of the study proposed by us take into account the well-being of young people, more precisely of students aged 13-14. We intend to reduce stress

* ADDRESS FOR CORRESPONDENCE: Vari Hanna Imola, Individual Sports - Faculty of Physical Education and Sport, Physical Education and Sport Faculty Romania, Babes - Bolyai University, Strada Mihail Kogalniceanu 1, 400000 Cluj-Napoca, Romania

E-mail address: hanna imola@yahoo.com
\end{abstract}


Grosu, F. E., Imola, V. H., Costinel, M., Teodor G. V. \& Adrian, M. T. A. (2020). Implementation of dance therapy in 13-14 year old students in order to reduce stress and anxiety. New Trends and Issues Proceedings on Humanities and Social Sciences. 7(3), pp 130-141. Available from: www.prosoc.eu

by applying intervention plans based on a succession of specific dance steps, an artistic program created by us especially for this purpose. Subjects, duration and place of study: The study took place between October 2016 and January 2017, in ClujNapoca, in the gym of the 'George Baritiu' National College, a number of 30 students. Tests and assessment tools used in research: To find out the emotional state of students, we apply: Relaxation technique R. Bandler, Jacobson, Endler Scale of Multidimensional Anxiety Assessment Test - Endler Scales for Multidimensional Anxiety Assessment (Anxiety Scale), Emotional Distress Profile. We use Statistical Package for the Social Sciences, for the analysis of three or more samples, the analysis of variance test was used in the case of data with normal distribution or the non-parametric Kruskal-Wallis test, in the case of values with uneven distribution or ranks. Conclusions and recommendations: The obtained results underline the importance of using psychological tests to detect the level of stress in order to decrease its intensity and to raise awareness of well-being. Following the results obtained, which are statistically significant, we conclude that students need a special intervention program created by us that will reduce the accumulated stress.

Keywords: Dance-therapy, stress, anxiety.

\section{Problem statement}

Investigating numerous articles and studies on the effects of dance on the body, we can say that this type of movement brings many benefits to our health both physically and mentally regardless of the age. Many cultures around the world agree that there is a connection between mind and body. Therefore, the use of dance to heal this damaged connection has become very common. During the African diaspora, people used dance therapy to treat experienced trauma (Delabary, Monteiro \& Rochelle, 2017).

It has been repeatedly demonstrated how dance influences people's mental health. For example, the main author of a stress-related study found that despite issues, such as stress and other challenges in a teenage girl's daily life, dancing can come as a positive experience for them.

Dance had the potential to contribute to new positive habits (Duberg, Hagberg, Sunvisson \& Moller, 2013). Swedish researchers investigated the case of teenage girls who had problems with back pain, stress, anxiety and depression. Half of the girls took part in dance classes twice a week and through this, they improved their mental health and increased their self-esteem (Duberg et al., 2013). In addition, a recent study in Australia looked at the use of dance for people with dementia. It has been shown that agitation symptoms have been reduced in people with dementia (Duignan, 2009). In general, dancing increased muscle strength and flexibility, improving overall movement. It has also improved balance, coordination and posture to reduce back pain (Ward, 2008).

Through dance - therapy has improved the quality of life of patients. In the short term, improvements have been made in social relationships and physical health, and in the long term, general and spiritual life have improved (Brauninger, 2012).

Following a study published in the journal The Arts in Psychotherapy, it was found that the dance therapy had a positive effect on participants suffering from depressive symptoms (Koch, 2007). Other researchers who have applied dance therapy to patients with severe depressive symptoms have had the same positive findings (Punkanen, Saarikallio \& Luck, 2014; Lee, 2015). Depression and anxiety were also significantly reduced in some German patients, in addition, positive effects were found on their mood and vision of their own body (Koch, 2007).

\section{Music therapy has also decreased the level of anxiety}

(Lee \& Le-Yung, 2012) Psychological distress, suffering and negative emotions are often felt by breast cancer patients (Romito \& Giotta, 2013). Italian researchers examined distress and negative emotions using The Emotion Thermometer Tool. This was administered before and after the intervention. The tool is a combination of visual scale that measures stress, anxiety, depression and anger. In the experiment group, stress, anxiety, depression and anger were significantly reduced. Integrative intervention can be considered useful in reducing negative emotions during the 
Grosu, F. E., Imola, V. H., Costinel, M., Teodor G. V. \& Adrian, M. T. A. (2020). Implementation of dance therapy in 13-14 year old students in order to reduce stress and anxiety. New Trends and Issues Proceedings on Humanities and Social Sciences. 7(3), pp 130-141. Available from: www.prosoc.eu

administration of chemotherapy, especially anger and depression. The concept of stress is very often mentioned in recent decades in industrialised societies, most works referring to environments and organisational groups, but also in informal social groups, sports teams, family space, in response to various requests (unpleasant events, illness, family incidents etc.).

The definition of stress belongs to Selye (1974), who was the representative of a physiological approach to this phenomenon: stress appears as an adaptive reaction of the individual to an event that bothers him. In other words, it is not the stressful situation that produces the stress, but the individual reaction to it. Selye identifies three phases in this response: resistance, alarm reaction and exhaustion, each having effects on the individual's psychophysical system (Selye, 1974, quoted from Laszlo, 2008). The author also emphasises the presence of multiple forms of reaction to stress, due to sets of causes, distinctive as stressors: personality, situational, social support, etc. The best known model for explaining stress, the interactive or transactional model was developed by Lazarus and Folkman (1984), representing the phenomenon in the context of the interaction between a person and his environment, as the individual's reaction to different situations he comes in contact with. Therefore, the stress is not the same as the stimulus or response of the person subjected to the stimulus, but is a process in which the person participates as an active agent, influencing the effects of coping with in the stressful situation through different cognitive, emotional and behavioral strategies. to put these strategies in practice (Lazarus \& Folkman, 1984).

There are two major senses in which stress is treated: the situational - when a stressful situation acts as a mental and physical stimulus and the physiological - when increased stress involves the mobilisation of mental and physical resources in response to sentimental threat, danger or overload (Baban, 1998; Spielberger, 1972). In response to the stimulus mediated by personality traits, stress has a sequential rhythm of installation, one of the conditions being the person's exposure to tension and pressure for a longer period, during which one or more areas of a person's life are affected: financial aspect, professional or marital status and health. Most of the time, the individual manages to recover on one or all levels when the stress stimulus disappears, but there can be damage, especially psychological (low self-esteem, post-traumatic stress disorder, etc.).

Today dance therapy is recommended for patients as a treatment for emotional and therapeutic support, because allows people to connect with their inner self (www.cancer.org.).

\section{Purpose of Study}

This work aims to analyse the level of stress in students aged 13-14 years, as well as reducing the level of stress felt by them by applying dance therapy. In everyday life, stress and anxiety can have negative effects on human physical and mental health, constantly looking for ways to reduce them through various methods and techniques. Applying artistic techniques improves students' results and optimises their behavior. By applying systems of specific means, the aim is to change the dysfunctional negative emotions before and after the dance: stress, anxiety, sadness, guilt. Positive emotions such as self-confidence and self-esteem increase.

\subsection{General purpose}

General purpose in conducting this research, it is proposed to develop an action strategy to reduce stress in students aged 13-14, through various artistic techniques, and evaluate the effectiveness of applied research methods. Therefore, as a general goal in conducting this research, it is proposed to develop an action strategy to reduce stress through various artistic techniques, and evaluate the effectiveness of applied research methods. At the same time, to determine the opportunity and efficiency of dance practice for students aged 13-14 in order to improve coordination and reduce stress. 
Grosu, F. E., Imola, V. H., Costinel, M., Teodor G. V. \& Adrian, M. T. A. (2020). Implementation of dance therapy in 13-14 year old students in order to reduce stress and anxiety. New Trends and Issues Proceedings on Humanities and Social Sciences. 7(3), pp 130-141. Available from: www.prosoc.eu

\subsection{Study hypothesis}

Indicators of stress (such as anxiety, emotional distress, etc.) can be improved with a focused dance-intervention therapy program, created specifically for this purpose. In this study, we sought to find out if these forms of stress are measurable, and if they can be alleviated through an active relaxation program (dance program).

\subsection{The objectives}

The objectives of the study proposed by us take into account the well-being of young people, more precisely of students aged 13-14 years. We intend to reduce stress by applying intervention plans based on a succession of specific dance steps, an artistic program created by us especially for this purpose. We will use steps from contemporary ballet, from classical dance, but also specific elements taken from rhythmic gymnastics and sports gymnastics.

\section{Subjects, duration and place of study}

The study took place between October 2016-April 2017, in Cluj-Napoca, in the gym of the 'George Baritiu' National College, on a number of 30 students. The inclusion of the subjects in the experiment was done on the basis of the informal consent regarding the purpose of the study and the work program. They were guaranteed confidentiality in connection with the use of the results obtained in the tests and trials applied. The group of students was a mixed one, made up of $45 \%$ boys and girls, respectively, $55 \%$.

\section{Tests and assessment tools used in preliminary research}

To find out the emotional state of students, and to determine whether these states are dependent on certain external factors, and whether these changes are measurable with the tests and tools we choose, in the preliminary study we chose to administer the following tests to the experimental and control group:

- Relaxation technique R. Bandler, JacobsonTestul Endler Scale of Multidimensional Anxiety Assessment (EMAS) -

- Endler Scales for Multidimensional Anxiety Assessment (Anxiety Scale)

- Emotional Distress Profile (PDE)

We used the PDE test which is a perfect means of research to measure the subjective dimension of negative perceptions both functional and dysfunctional.

What does the scale measure? The PDE consists of 26 items designed to measure dysfunctional negative emotions and functional negative emotions in the 'fear' and 'sadness/depression' categorisations. With the help of this scale we can calculate a general distress score, as well as separate scores for 'functional fear', for 'dysfunctional fear', for 'functional sadness/depression' and for 'dysfunctional sadness/depression'. The Scale of the PDE was created in 2005 (Opris \& Macavei, 2005), based on the items of the PDE, the short version (DiLorenzo, Bovbjerg \& Montgomery, 1999). These elements were later enriched with concepts that describe emotions identified through the use of a dictionary of synonyms. The last version, which contains a total of 26 items, forms the final version of the PDE scale, and resulted from expert validation and several practical studies to establish the relevance and subscales in which it falls.

The EMAS scale consists of five tools, and they assess anxiety as a state, as a trait and the perception of the individual to his threat in a situation. These scales, called EMAS, are used to assess the level of anxiety. Emas S measures anxiety as a condition. Emas T measures anxiety as a trait. Emas 
Grosu, F. E., Imola, V. H., Costinel, M., Teodor G. V. \& Adrian, M. T. A. (2020). Implementation of dance therapy in 13-14 year old students in order to reduce stress and anxiety. New Trends and Issues Proceedings on Humanities and Social Sciences. 7(3), pp 130-141. Available from: www.prosoc.eu

P measures anxiety as perception. They are multidimensional, so the scales allow the interpretation of test results and the association of scores obtained with other areas of personality functioning. The test indicates the amplitude of anxiety-like reactions of individuals and the individual pattern of anxiety reactions in different situations.

\section{The objectives of the study}

The objectives proposed by us take into account the well-being of students aged 13-14. We intend to reduce stress by applying intervention plans based on a succession of specific dance steps, an artistic program created by us especially for this purpose. We will use steps from contemporary ballet, from classical dance, but also specific elements taken from rhythmic gymnastics and artistic gymnastics. Applying artistic techniques improves students' results and optimises their behavior. By applying systems of specific means, the aim is to change the dysfunctional negative emotions before and after the dance: stress, anxiety, sadness, guilt. Positive emotions such as self-confidence and selfesteem increase.

\section{Hypothesis of the study}

At the same time, these indicators of stress (such as anxiety, emotional distress, etc.) can be improved with a focused intervention program, created especially for this purpose. Therefore, in our preliminary study, we looked to find out if these forms of stress are measurable, and if they can be alleviated through an active relaxation program (dance program).

\section{Methods}

Knowing the multiple therapies that help to achieve human physical and mental well-being, we chose the intervention through dance as a method to help reduce stress and improve school results for young people aged 13-14. Therefore, we proposed an action system, an intervention plan that can be applied during physical education and sports classes, using the specific means of dance.

\subsection{The PDE test}

The PDE test is the more effective as it allows not only to estimate a global value of distress, but also allows the separate calculation of scores for functional fear, for dysfunctional fear, for functional sadness/depression as well as for functional or dysfunctional negative emotions. Another advantage of the PDE scale is that the relatively small number of items it contains are formulated in an easy-tounderstand language, making the administration and rating of the scale more accessible to the interested audience.

\section{Intervention schedule - models for dance - therapy}

Dance therapy can be performed through the method called 'Primitive Expression' or 'Dance therapy in Afro-Latin rhythm'. We will set out below the main features of Dance Therapy: 
Grosu, F. E., Imola, V. H., Costinel, M., Teodor G. V. \& Adrian, M. T. A. (2020). Implementation of dance therapy in 13-14 year old students in order to reduce stress and anxiety. New Trends and Issues Proceedings on Humanities and Social Sciences. 7(3), pp 130-141. Available from: www.prosoc.eu

1. The implicit condition for the existence of the 'Primitive Expression' lesson is represented by the existence of percussion instruments and their use. All movements are performed at the rhythm performed by the instrumentalists, https://www.youtube.com/watch?v=EyhjIVBLU5g

2. The characteristic of the primitive expression are the movements: playful, friendly, communication and exchange of opinions through movement with other children or colleagues.

The facets of therapeutic dance refer to rhythm and tempo. When rhythm takes place in a unit of time, we are talking about tempo. The same movements can take place more slowly or faster, in a longer or shorter period of time.

3. Soft energy taken from the 'tribe', a group in our case, through soft and rounded movements made to the rhythm of the drums, https://www.youtube.com/watch?v=EyhjlVBLU5g

4. Introspection and joy

Dance therapy by primitive expression is performed through activities carried out in small groups tribe. The psychological characteristics of this type of dance therapy are expressed by: increasing the capacity for introspection, joy by moving with the alternative raising of the arms and raising both arms to the rhythm. (https://www.youtube.com/watch?v=EyhjlVBLU5g)

Students move to the rhythm of the music and alternately raise the right or left arm of their choice, or both arms to the rhythm. The arms rise in all three directions: up, sideways, back and forth. The arms can be bent or stretched.

From time to time the participants form groups of 2-3 people spontaneously, dynamically and playfully.

5. Physiological characteristics: learning to move on rhythm and awareness of increased heart rate, photo 38 , accompanied by the voices of participants with cries of joy on rhythm, type: 'ha, ha - he, he' and 'hi, hi - ho, ho'

6. The use of simple movements, of symbolic gestures, to express different emotions of a playful nature.

It will work in such a way that even the most restrained participants express themselves in very simple movements.

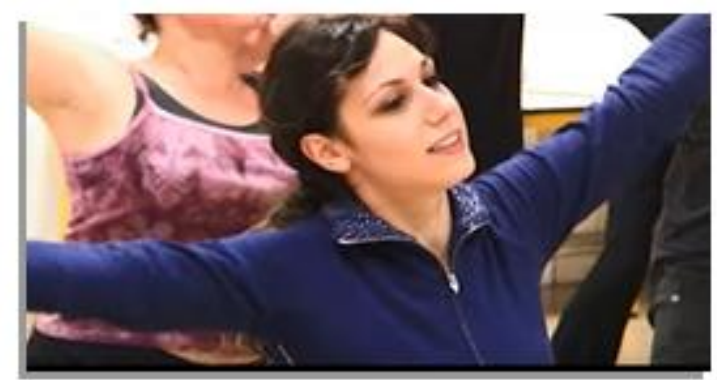

Figure 1. Simple gestures and movements 

order to reduce stress and anxiety. New Trends and Issues Proceedings on Humanities and Social Sciences. 7(3), pp 130-141. Available from: www.prosoc.eu

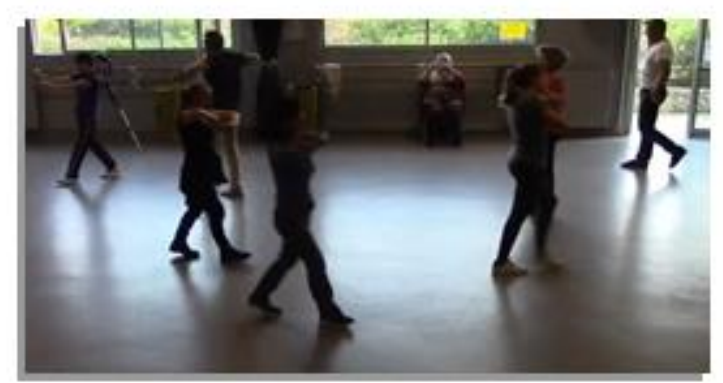

Figure 2. Simple gestures and movements

7. Dance jumps - therapy can be done with heels sitting, with movements of 5-7 jumps forward repeated five repetitions and jumps back five repetitions.

8. Fixing the Earth, making the participants aware that they belong to nature, to the Earth.

There are bending exercises, stretching the knees and jumping imitating the jump of a bunny.

9. Unison participation, all students at once: you can work in a large group (with the whole group of students), unison movements and unison activities.

10. Self-exploration and reconnection with the student on the inside through self-exploration and reconnection movements and repetition of rhythmic movements.

11. The jubilation of the repetition and its trance power framed by the rhythm, The repetition of the rhythmic movements, The warrior's game through offensive movements - of attack and defense.

12. Channeling our impulses to the warrior's game.

13. The training of dancers can be done in an ordinary room and can take place in a smaller group, or in a larger group - collectively, using interjections and songs consisting of repetitive syllables, during the dance. Group of dancers moving and singing.

14. The dance is performed through repetitive, playful movements, and often in contrast. Dancers need space for freedom, transforming any movement from dance into joy: repetitive, contrasting movements. There will be movements with Large space between dancers

15. Recovery of the body by simple movements performed from lying on back (Figures 3 and 4) exercises performed in slow tempo.

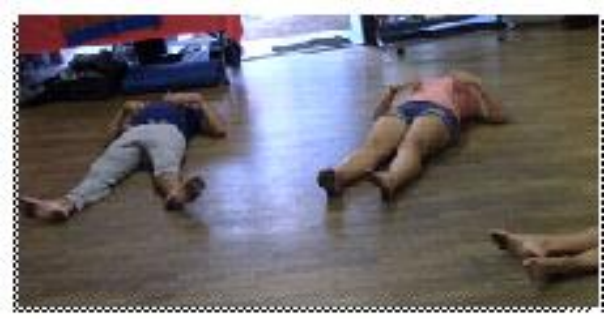

Figure 3. Return of the body

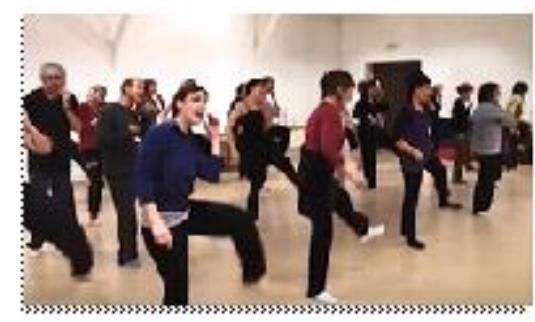


Grosu, F. E., Imola, V. H., Costinel, M., Teodor G. V. \& Adrian, M. T. A. (2020). Implementation of dance therapy in 13-14 year old students in order to reduce stress and anxiety. New Trends and Issues Proceedings on Humanities and Social Sciences. 7(3), pp 130-141. Available from: www.prosoc.eu

Figure 14. Simple movements for the return of the body

16. From sitting with bent legs, all participants in the circle discuss the lesson and the teacher expects feedback from his students. Moments of relaxation, reconnection. Exercises performed in slow tempo.

17. Sharing the experience of the session in pairs and then in groups.

Sitting in a circle - walking on the rhythm of the music with shouts of joy on the music (hua-huahua) and swinging his arms back and forth Moment of relaxation and reflection. The end of the lesson takes place when the percussion is interrupted in a still position, with a collective cry with the sharing of experience.

\section{Closing the workshop with collective energy with the Completion of the lesson.}

\section{Data processing and interpretation}

We used statistical indicators for the R. Bandler, Jacobson, EMAS, PDE tests.

Statistical indicators - Elements of descriptive statistics were calculated, the data being presented using indicators of centrality, location and distribution.

Statistical analysis - The Shapiro-Wilk test was used to test the normal distribution. The variance was tested with the F or Levene and/or Bartlett tests.

In the case of data with normal distribution, the $t$ (Student) test was used, and in the case of nonuniform distribution values or ranks, non-parametric Mann-Whitney (U) tests were used for two unpaired samples, or Wilcoxon in the case of two paired samples. For the analysis of three or more samples, the analysis of variance test was used in the case of data with normal distribution or the nonparametric Kruskal-Wallis test, in the case of values with uneven distribution or ranks. The significance threshold for the tests used was $\alpha=0.05(5 \%), \alpha=0.01(1 \%)$ or $\alpha=0.001$, as follows: $0.01<p<0.05$ - statistically significant difference; $0.001<p<0.01$ - very statistically significant difference; $p<0.001$ - statistically significant high difference; $p>0.05$ - statistically insignificant difference.

The Pearson correlation coefficient $(r)$ was used to detect the correlation between two continuous quantitative variables with normal (uniform) distribution. In the case of variables with uneven distribution, the correlation coefficient of the Spearman ranks $(\rho)$ was used. The analysis of the correlation coefficients was performed using Colton's rule.

Thus, starting from the properties of the correlation coefficient that say that this is a number between -1 and 1 and that the 'intensity' of the linear relationship between the two variables will be even higher as the correlation coefficient approaches 1 in absolut value, Colton (1974) suggested the following empirical rules for interpreting the correlation coefficient:

- weak/zero correlation if $r \in[-0,25,+0,25]-$ noted $^{*}$

- $\quad$ acceptable correlation if $r \in(+0,25,+0,5] \cup[-0,5,-0,25)$ - noted $* *$

- good correletion if $r \in(+0,5,+0,75] \cup[-0,75,-0,5)$ - noted $* * *$

- very good correletion if $r \in(+0,75,+1] \cup[-1,-0,75)$ - noted $* * * *$

Polynomial regression was the method used to obtain the mathematical equation of the dependence of one continuous variable on another variable.

The statistical processing was performed with the Excel application (from the Microsoft Office 2007 package), with the StatsDirect v.2.7.2 program. The graphical representation of the results was done with the Excel application (from the Microsoft Office 2007 package). 
Grosu, F. E., Imola, V. H., Costinel, M., Teodor G. V. \& Adrian, M. T. A. (2020). Implementation of dance therapy in 13-14 year old students in order to reduce stress and anxiety. New Trends and Issues Proceedings on Humanities and Social Sciences. 7(3), pp 130-141. Available from: www.prosoc.eu

\section{Results and statistical analysis of the tests}

Time 1 = initial testing and Time 2 = final testing

Comparing the results of the two measurements (from the beginning and the end of the intervention period) we managed to record in the tests used certain values that mean statistically significant changes between the two time points. These results, together with the statistical explanation, are presented in the tables and graphic below. At the end, the correlations between the indicators of the tests applied in the study will be presented. Experimental group - 30 students aged 13-14 years (intervention period 3 months).

We can see the results of the test items, following statistical analyses in Table 1:

Table 1. R. Bandler, Jacobson, EMAS, PDE, AP2, MA, AD tests and statistical significance

\begin{tabular}{lcccccccc}
\hline Indicators & Time & Average & ES & Mediana & DS & Min & Max & Statistical significance (p) \\
\hline \multirow{2}{*}{ R. Bandler } & 1 & 29.13 & 1.6468 & 32 & 9.0200 & 13 & 44 & \multirow{2}{*}{0.038} \\
& 2 & 34.43 & 1.3786 & 34.5 & 7.5507 & 17 & 54 & \\
\multirow{2}{*}{ Jacobson } & 1 & 39.40 & 1.6474 & 40 & 9.0233 & 18 & 57 & 0.1366 \\
\multirow{2}{*}{ EMAS } & 2 & 43.83 & 2.1157 & 43.5 & 11.5880 & 22 & 79 & \\
\multirow{2}{*}{ PDE } & 1 & 30.57 & 1.4752 & 30.5 & 8.0801 & 20 & 50 & 0.1269 \\
& 2 & 35.13 & 2.0414 & 32 & 11.1811 & 20 & 70 & \\
& 1 & 15.57 & 2.4540 & 13.5 & 13.4413 & 1 & 65 & $<0.0001$ \\
\hline
\end{tabular}

No statistically significant differences were observed between the two times $(p>0.05)$ in the statistical analysis of the values for the EMAS.

From this result it can be deduced that the intervention program in the pilot study did not have a pronounced effect on the amplitude of anxiety reactions. There are two ways to explain this:

- dance exercises in general will not have an impact on the individual pattern of anxiety reactions in different situations of the individual

- or the intervention program (three months) was too short to cause a measurable difference in this respect;

\section{Statistical correlation analysis for test values}

- $\quad$ at the initial testing (T1)

$\circ$ an acceptable and meaningful correlation with the Jacobson and PDE tests - this result indicates that if relaxation methods are applied and executed more effectively, we can expect an improvement in the perception of emotional distress and negative emotions such as 'fear' or 'sadness'

In the statistical analysis of the values for the emotional distress test (PDE), statistically significant differences were observed between the two times $(p<0.001)$. These values can be seen as marked in blue in the table above. The result obtained at this indicator shows us the considerable difference of the subjective dimension of negative perceptions.

\section{Findings and results}

- a weak/zero correlation with the EMAS test.

- at the final test (T2) - a weak/zero correlation with the Jacobson, EMAS, PDE tests.

These results show that the dynamics of the results measured following the intervention plan are not correlated with each other. 
Grosu, F. E., Imola, V. H., Costinel, M., Teodor G. V. \& Adrian, M. T. A. (2020). Implementation of dance therapy in 13-14 year old students in order to reduce stress and anxiety. New Trends and Issues Proceedings on Humanities and Social Sciences. 7(3), pp 130-141. Available from: www.prosoc.eu

Statistical correlation analysis for Jacobson test values showed:

- at the initial test (T1) - a weak/zero correlation with EMAS, PDE tests.

Statistical correlation analysis for EMAS scale values showed a weak/zero correlationwith PDE tests in both TI (initial testing) and TII (final testing).

Table 2. Statistical analysis of correlation between test values R. Bandler, Jacobson, EMAS, PDE

\begin{tabular}{llcccc}
\hline \multicolumn{2}{c}{ Indicators } & \multicolumn{2}{c}{ Time 1 } & \multicolumn{2}{c}{ Time 2 } \\
\hline \multirow{3}{*}{ R. Bandler - } & Jacobson & 0.3488 & $* *$ & 0.0713 & $*$ \\
& EMAS & -0.1385 & $*$ & 0.0054 & $*$ \\
Jacobson - & PDE & 0.2697 & $* *$ & 0.0056 & $*$ \\
EMAS - & EMAS & 0.0257 & $*$ & 0.1612 & $*$ \\
& PDE & -0.2268 & $*$ & -0.0894 & $*$ \\
PDE - & PDE & -0.2104 & $*$ & -0.1312 & $*$ \\
& AP2 & -0.2122 & $*$ & -0.2421 & $*$ \\
& MA & -0.1703 & $*$ & 0.2527 & $* *$ \\
& AD & 0.0242 & $*$ & -0.1004 & $*$ \\
\hline
\end{tabular}

The instreument is the more effective as it allows not only to estimate a global value of distress, but also allows the separate calculation of scores for functional fear, for dysfunctional fear, for functional sadness/depression as well as for functional or dysfunctional negative emotions. Another advantage of the PDE scale is that the relatively small number of items it contains are formulated in an easy-to-understand language, making the administration and rating of the scale more accessible to the interested audience.

\section{Discussions}

Different experiences, such as fear, satisfaction, regret, worry, anger, sadness or joy have their origins in the specific association between thinking, behavior and biophysiological changes in our body when faced with an impact situation in our lives, Tohanean (2015). Emotions are actually dependent variables or attributes with which people describe a series of sensory alterations that have occurred at different levels (David, Schnur \& Birk, 2004). When an emotion occurs, its intensity will be set at the level of physiological reactions, and the quality of the emotion (if we call it 'anger' and not 'upset') will be decided by the particularity of the cognitive construction involved (David et al., 2004; Schachter \& Singer, 1962).

Although at a common sense level emotions are felt as a community of feelings in a complex interaction, research has shown that the whole variety of emotions we feel is actually limited to a few basic feelings. Therefore, following multiple studies, Watson, Lagow, Xu, Zhang and Bonini (1988) concluded that the structure of affect has two dimensions, which are not correlated with each other: negative and positive emotions. Positive emotions are appreciated by the extent to which an individual experiences satisfaction and pleasure, while negative emotions are determined by the intensity of discomfort experienced (psychological distress).

Differences of a subjective nature between functional negative feelings and dysfunctional negative perceptions have been targeted and studied in several studies; the results of these studies show the presence of differences between the two types of emotions, both qualitatively and quantitatively (David et al., 2004; Opris \& Macavei, 2005). Relaxation has a favorable impact on the self-efficacy of cancer patients and can be adopted as a simple, cheap and affordable strategy for them, according to the results of a study conducted on 80 cancer patients (Norozi, Masmouei \& Harorani, 2018). A study of asthma patients showed that those in the experiment group had a much lower level of stress, and a better quality of life in terms of the symptoms of the disease, their daily activity and their emotional functions than the patients. from the control group (Gebhardt, Dammann \& Loescher, 2018). 
Grosu, F. E., Imola, V. H., Costinel, M., Teodor G. V. \& Adrian, M. T. A. (2020). Implementation of dance therapy in 13-14 year old students in order to reduce stress and anxiety. New Trends and Issues Proceedings on Humanities and Social Sciences. 7(3), pp 130-141. Available from: www.prosoc.eu

Progressive relaxation helps to reduce excessive sweating and reduce heart rate, according to a study conducted on young people to reduce stress (Peciuliene, Perminas, Gustainiene, \& Jarasiunaite, 2015). Studies show that progressive relaxation is an effective way to prevent nausea and vomiting and to improve the mental state of breast cancer patients (Kapogiannis, Tsoli \& Chrousos, 2018).

\section{Conclusions and recommendations}

In order to meet the requirements of the Helsinki Declaration, Directive 86/609/EEC and the regulations of the Ethics Commission of the institutions where the studies were carried out, we have previously obtained the informal agreement from the school, required in the research for studies on children and the agreement, respectively the collaboration of the sports teacher in the development without risks and impediments, of any nature, of the research. The research took place in a relaxing and trusting atmosphere.

The obtained results underline the importance of using psychological tests to detect the level of stress in order to decrease its intensity and to raise awareness of well-being.

Following the results obtained, which are statistically significant, we conclude that students need a special intervention program created by us that will reduce the accumulated stress, Tohanean and Turcu (2018). We observed in our study how certain indicators can be improved by practicing a sport dance moment with art therapy effect.

Students were able to use relaxation techniques more effectively ( $R$. Bandler, Jacobson) as a result of which they were able to improve their PDE and the quality of attention perception.

Therefore, the hypothesis of the preliminary study confirms that indicators of stress (such as anxiety, emotional distress, etc.) are attributes that can be improved with an intervention program, as well as the fact that these psychological components (of stress) are measurable, and their evolution can be tested. Following the preliminary research, through these tests, the testing tools and experimental conditions were validated. Thus, the results obtained from the tests performed by applying the tests: R. Bandler and Jacobson, EMAS, PDE entitle us to conclude that the advanced hypotheses in the preliminary research are validated, which gives us the opportunity to continue the research.

\section{References}

Baban, A. (1998). Stres si personalitate. Cluj-Napoca, Romania: Presa Universitara Clujeana.

Brauninger, I. (2012). Dance movement therapy group intervention in stress treatment: a randomized controlled trial (RCT). The Arts in Psychotherapy, Elsevier, 39(5), 443-450.

David, D., Schnur, J. \& Birk, J. (2004). Functional and dysfunctional feelings in Ellis' cognitive theory of emotion: an empirical analysis. Cognition and Emotion, 18, 869-880.

Delabary, M., Monteiro, E., \& Rochelle, C. (2017). Effects of dance practice on functional mobility, motor symptoms and quality of life in people with Parkinson's disease: a systematic review with meta-analysis. Aging Clinical and Experimental Research, 30, 1-9. doi:10.1007/s40520-017-0836-2.

Duberg, A. (2012). Dancing and the brain - Department of Neurobiology. JAMA Pediatrics.

Duberg, A., Hagberg, L., Sunvisson, H. \& Moller, M. (2013). Influencing self-rated health among adolescent girls with dance intervention. JAMA Pediatrics, 167(1), 27-31.

Duignan, D. (2009). Exploring dance as a therapy for symptoms and social interaction in a dementia care unit. London, UK: Nursingintimes.net.

Gebhardt, S., Dammann, I. \& Loescher, K. (2018). The effects of music therapy on the interaction of self and emotions - an interim analysis. Complementary Therapies in Medicine, 41, 61-66. 
Grosu, F. E., Imola, V. H., Costinel, M., Teodor G. V. \& Adrian, M. T. A. (2020). Implementation of dance therapy in 13-14 year old students in order to reduce stress and anxiety. New Trends and Issues Proceedings on Humanities and Social Sciences. 7(3), pp 130-141. Available from: www.prosoc.eu

Kapogiannis, A., Tsoli, S. \& Chrousos, G. (2018). Investigating the effects of the progressive muscle relaxationguided imagery combination on patients with cancer receiving chemotherapy treatment: a systematic review of randomized controlled trials. EXPLORE.

Koch, S. C. (2007). The joy dance: specific effects of a single dance intervention on psychiatric patients with depression. The Arts in Psychotherapy, 34(4), 340-349.

Lazarus, R. S. \& Folkman, S. (1984). Stress, appraisal, and coping. New York, NY: Springer Publishing.

Lee, J. (2015). A study on the relationship between stress and fatigue and the musculoskeletal symptoms experienced by Korean radiation workers. Journal of Physical Therapy Science, 27(2), 427-431.

Lee, C. \& Le-Yung, W. (2012). European Journal of Oncology Nursing, 17(4), 436-441.

Norozi, M., Masmouei, B. \& Harorani, M. (2018). The effect of progressive muscle relaxation on cancer patient's self-efficacy. Complementary Therapies in Clinical Practice, 34, 70-75.

Opris, D. \& Macavei, B. (2005). The distinction between functional and dysfunctional negative emotions; an empirical analysis. Journal of Cognitive and Behavioral Psychotherapies, 5, 181-195.

Peciuliene, I., Perminas, A., Gustainiene, L. \& Jarasiunaite, G. (2015). Effectiveness of progressive muscle relaxation and biofeedback relaxation in lowering physiological arousal among students with regard to personality features. Procedia-Social and Behavioral Sciences, 205, 228-235.

Punkanen, M., Saarikallio, S. \& Luck, G. (2014). Emotions in motion: short-term group form dance/movement therapy in the treatment of depression: a pilot study. The Arts in Psychotherapy, 41(5), 493-497.

Romito, F. \& Giotta, F. (2013). Music Therapy and emotional expression during chemotherapy. How do breast cancer patients feel? European Journal of Integrative Medicine, 5(5), 438-442.

Schachter, S. \& Singer, J. (1962). Cognitive, social, and physiological determinants of emotional state. Psychological Review, 69(5), 379-399. doi:10.1037/h0046234

Selye, H. (1974). Stress and distress in response to psychosocial stimuli (pp. 5-6). Pergamon, Turkey: Elsevier.

Spielberger, Ch. D. (1972). Anxiety as an emotional State. In: C. D. Spielberger (Ed.), Anxiety: current trends in theory and research. New York, NY: Academic Press.

Tohanean, D. I. (2015). Sport psychology. Selection and hemisphericity in the handball game (p. 172). Brasov, Romania: Publishing House of the Transilvania University of Brasov.

Tohanean, D. \& Turcu, I. (2018). The stress level of sports students reported to main temperament type. Gymansium, Scientific Journal of Education, Sport and Health, XIX(2), 88-93.

Ward, S. (2008). Health and the power of dance. Journal of Physical Education, Recreation and Dance, 79(4), 33-36.

Watson, M. R., Lagow, R. D., Xu, K., Zhang, B., Bonini, N. M. (2008). A drosophila model for amyotrophic lateral sclerosis reveals motor neuron damage by human SOD1. Journal of Biological Chemistry, 283(36), 24972-81. Retrieved from https://www.youtube.com/watch?v=EyhjlVBLU5g) 